\title{
Artigo
}

\section{A História da Cidade contada pela perspectiva do observador: um estudo sobre a identidade de Ipiabas e Conservatória por meio de um projeto de extensão}

The City History through the observer's perspective: a study on the identity of Ipiabas and Conservatória in a Community Project

Jacqueline de Cassia Pinheiro Lima', Idemburgo Pereira Frazão Félix², José Geraldo da Rocha ${ }^{3}$

\begin{abstract}
"A história faz-se com documentos escritos, sem dúvida. Quando estes existem. Mas, pode fazer-se, deve fazer-se sem documentos escritos, quando não existem".
\end{abstract}

Lucien Febure

\section{Considerações Iniciais}

O Projeto de Extensão "Memória e identidade: um estudo da relação da representação social com o cotidiano das manifestações musicais de Conservatória, Ipiabas e região" é, em sentido amplo, um grande exercício de reflexão e ação interdisciplinar e dá ênfase a questões relativas à "serenata de conservatória" - evento que, ao longo de décadas tem encantado centenas pessoas, em sua grande maioria, idosos - refletindo sobre a importância da memória como mecanismo de "ação cultural", ou como recurso, para lembrar dos estudos de George Yudice. O eixo das discussões implementadas no Projeto está centrado nas reflexões sobre o desenvolvimento social e econômico de uma região que, no passado teve como principal atividade econômica a produção do café e que, hoje, tem como fonte de arrecadação, o turismo.

A permanência de um importante "clima" histórico, remanescente do período áureo das plantações de café, marcadamente presente nas fachadas dos casarios e nos eventos realizados no Distrito de Conservatória, tem atraído turistas e impulsionado o desenvolvimento cultural e econômico na região estudada. Atividades que remetem os visitantes a lugares e sabores que vão do aroma do café dos tempos antigos ao som das melodias dolentes da "Era do Rádio", fazendo da me-

\begin{abstract}
Resumo
Apresentamos aqui um estudo de duas cidades a partir de um Projeto de Pesquisa e Extensão apoiado pela FAPERJ no ano de 2010. A importante questão deste texto é a do reconhecimento do que seria ou não história, pertencimento, identidade e construção de uma marca que estabeleça um vínculo entre a cidade e seus moradores e entre a cidade e seus visitantes. Assim são as histórias de dois distritos no Estado do Rio de Janeiro: Ipiabas e Conservatória. Dois lugares cheios de história, mas que em suas manifestações ora esbarram com a falta de reconhecimento dos costumes que trazem a marca da cidade e sua identidade, como ocorre com Ipiabas, e ora se confundem entre o que quer a tradição e o que a modernidade espera de Conservatória.
\end{abstract}

Palavras-chave: História; Memória; Pertencimento; Ipiabas; Conservatória

Área Temática: Interdisciplinar Linha de Extensão:Gênero, Etnia e Identidade
I Coordenadora e Professora do Programa de Pós-Graduação em Letras e Ciências Humanas da UNIGRANRIO. E-mail: jpinheiro@unigranrio.com.br 2 Professor do Programa de Pós-Graduação em Letras e Ciências Humanas da UNIGRANRIO. E-mail: idfrazao@uol.com.br

3 Professor do Programa de Pós-Graduação em Letras e Ciências Humanas da UNIGRANRIO. E-mail: rochageraldo@hotmail.com 
mória um elemento especial. Há nesse instante, para quem viveu aqueles momentos, uma viagem no tempo, no seu tempo, no tempo da memória. Como afirma Ecléa Bosi: "A memória é, sim, um trabalho sobre o tempo, mas sobre o tempo vivido, conotado pela cultura, pelo indivíduo" ${ }^{1}$. As fazendas habitadas pelos famosos Barões do Café com seus inúmeros escravos, as praças e os casarios, que se tornariam, definitivamente passado, se renovam, tornam-se presente(s).

Hoje, esse cenário bucólico é o local onde se desenvolvem atividades que vêm atraindo enormes quantidades de visitantes. A serenata de Conservatória e outras manifestações culturais (como o jongo e a capoeira) desenvolvidas nos municípios de Valença e Barra do Piraí, são atividades culturais que se transformaram, ou podem se transformar (no caso de Ipiabas), em importantes meios de desenvolvimento cultural e econômico, trazendo inúmeros benefícios para a sua região.

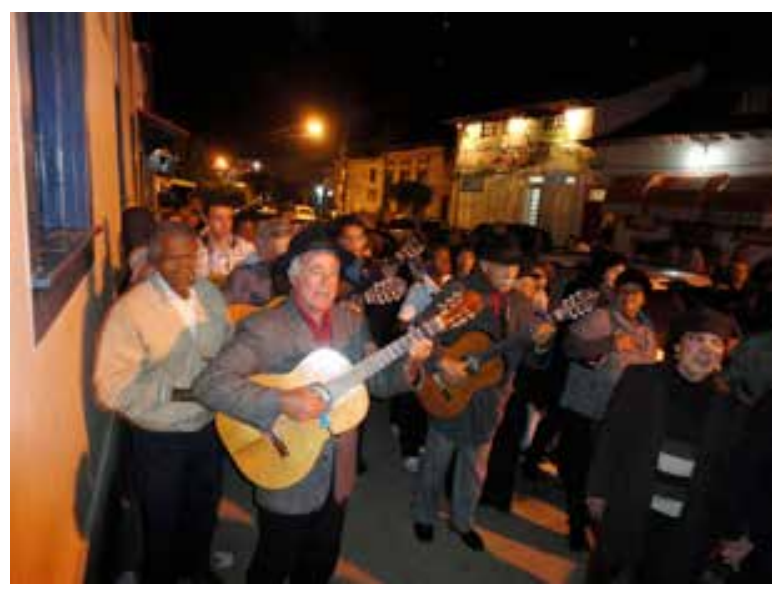

Serenata em Conservatória foto da equipe -2010

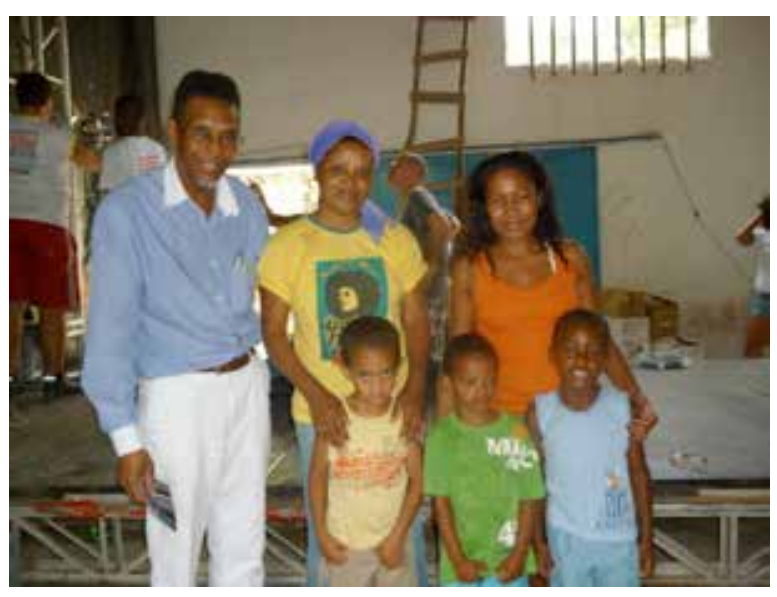

Atividade em Ipiabas - foto da equipe - 2010

\section{Antecedentes Históricos}

A preocupação em se mostrar os antecedentes históricos das duas localidades se dá em função de se fazer relacionar o movimento e a identidade de cada uma delas e o envolvimento dos sujeitos históricos que as constroem e lhes dão sentido.

A tarefa de escrever sobre a História de uma cidade e de seus costumes torna-se bastante interessante e difícil. Interessante porque vamos encontrar e percorrer caminhos ora muito conhecidos por uns, ora completamente distantes de outros. Difícil porque contar a história é recontar o que já se sabe por alguém, por um grupo e esse recontar faz surgir novas questões que estavam esquecidas no tempo, no espaço. Para discutirmos teoricamente estas questões, como uma boa história, primeiro vamos aos fatos. Quem são essas personagens chamadas Ipiabas e Conservatória?

Ipiabas nasceu das chamadas sesmarias no sertão de Valença no fim do século XVIII que foram habitadas de início pelo grupo indígena Coroados, que aos poucos foram desaparecendo. O Distrito de Ipiabas só veio a ser construído em 1838, tornando-se Freguesia em 1952. Muitos decretos se passaram até que em 1943 veio fazer parte de Barra do Piraí.

Hoje, algumas construções são marcas do centro histórico, embora pouco reconhecidas como tal. São elas: o cemitério construído em 1856, sendo que a Câmara de Valença deu ordem e dinheiro para a construção de um novo cemitério na Freguesia em 1874 e a Matriz de Nossa Senhora da Piedade construída em 1870. Dali em diante, a iluminação pública a querosene estava garantida. Passado os anos, foram construídas fábricas de queijos, criação de animais, hortaliças, destaque para a plantação de café e a chegada das pousadas e hotéis transformaram Ipiabas em um lugar turístico.

Ipiabas tem uma tradição de bordado bastante presente. A partir de 2009 surgiu o projeto Bordando o Vale, uma parceira entre o Centro Cultural Aracy Carvalho Di Biasi e do Centro Universitário Geraldo Di Biasi (UGB) e o Projeto Social Amor-Perfeito.

Com o objetivo de valorizar a memória como construtora de identidades, fazemos um resgate da história local através de relatos e pesquisas. Estabelecendo linhas temáticas de trabalho, os borda- 
dos são feitos a partir dos desenhos de Maria José Marchiori. Os produtos confeccionados compõem exposições e são comercializados. (Luana Oliveira, Coordenadora do Centro Cultural).

De valiosa importância alguns prédios em Ipiabas ainda guardam valores incontáveis: a Igreja de Nossa Senhora da Piedade, erguida a partir de 1812 e atualmente restaurada. O Casarão da Antiga Remonta de 1874 foi ponto das tropas da Guarda Imperial, que descansavam e alimentavam seus cavalos. No fim dos 1800 conta-se que foi confiscado por falta de pagamento de impostos e assim doado ao Exército que lá se instalou o Quartel da Remonta em fevereiro de 1930 e a Fazenda São Joaquim das Ipiabas, fundada em 1820 pelo, mais tarde, primeiro Barão do Rio Bonito.

Embora muito atrativa, os moradores de Ipiabas não reconhecem a tradição africana, sequer talvez conheçam o passado indígena. Tem personagens interessantes na Cidade além dos monumentos deixados como lugares-de-memória que poderiam marcar tal identificação, mas que acabam não o fazendo. O jongo, a capoeira como manifestação cultural, as bonecas de pano símbolo da região, o casarão que hoje abriga um restaurante e a própria ideia da relação com Conservatória, não se traduzem como um olhar atento da população.

Quando falamos da relação com Conservatória não queremos estabelecer uma dependência, mas tínhamos a impressão que a música poderia ser um elo entre as duas localidades, assim como havia uma tendência a um afastamento, por conta de algum tipo de competição entre elas. Como se Ipiabas tivesse que ser um espelho de Conservatória, ou simplesmente abrigar suas tradições.

Neste sentido, os monumentos, algumas personagens, bem como a o universo cultural funcionariam como lugares-de-memória, como na concepção de Pierre Nora². Segundo o autor os "lugares-de-memória" podem ser monumentais, tendo seu significado em sua própria existência, ou arquiteturais, no que dependem da relação com a sua própria época. Eles caracterizam-se por não terem um referencial preso à realidade, mas por serem fechados em si mesmos, sobre suas identidades, e abrirem-se quanto a suas significações.

Lugares, mas lugares mistos, híbridos e mutantes, intimamente enlaçados de vida e de morte, de tempo e de eternidade; numa espiral do coleti- vo e do individual, do prosaico e do sagrado, do imóvel e do móvel ${ }^{3}$.

Conservatória, como seu próprio nome indica conserva esse lado turístico com muito mais propriedade. Lugar das serestas ou serenatas, como seus habitantes chamam, o lugar tem enraizado a música como sua identidade. Identidade esta que atrai a tradição e repele e modernidade. Os jovens de hoje não veem em Conservatória um futuro para eles se a música tocada e cantada não se transformar.

Alguns se dedicam a esta tradição, mas em sua maioria acabam vendo a cidade como um lugar para turistas e por isso pensa em deixar a Cidade. Neste sentido nos perguntamos: uma cidade que vive de seu passado pode se pensar sem seu futuro? Bem, mas que passado foi este?

Conservatória dos Índios, atualmente conhecida somente por Conservatória, se já é hoje considerada um dos principais pontos de observação de ovnis, já foi dominada pelos índios Purus ou Araris no final do século XVIII. Desenhada sua planta em 1838 pelo mesmo homem que o fez em Valença, Conservatória transformou-se em Freguesia cinquenta e quatro anos depois. Com sua capela dedicada a Santo Antonio construída no mesmo ano em 1845 constrói-se o cemitério. Mas, logo a capela sofreria um incêndio e a Matriz seria construída a partir de 1850 .

Durante o final do século XIX quatro escolas foram construídas, sendo duas delas somente para meninos, um novo cemitério começara a ser construído, assim como iniciou o primeiro abastecimento de água para a Freguesia e o calçamento da Rua Direita. Tão logo, a iluminação a querosene apareceria assim como a construção da ferrovia, inaugurada por Dom Pedro II. O ano de 1880 marca a construção de dois monumentos importantes à história de Conservatória: o Túnel que chora que tem esse nome por causa das gotas que caem dele e a Ponte dos Arcos. Chega o século XX e depois de surto de febre amarela e nuvem de gafanhotos, instala-se em 1919 a iluminação elétrica.

O ano de 1938 é um ano chave: primeiro o distrito passa a se chamar Rio Bonito, depois, muda para Conservatória e funda-se o Conservatória Futebol Clube. Cinco anos mais tarde, Conservatória passa de Valença a pertencer à Barra do Piraí, até 1948. Passados os anos na década de 
60 do século XX abre-se a estrada de terra entre Conservatória e Barra do Piraí, mas só trinta e sete anos mais tarde o trecho Ipiabas/Conservatória é asfaltado.

A cidade, hoje distrito do município de Valença, cresceu durante o ciclo do café tendo abrigado mais de 100 fazendas, café este que era escoado pelo caminho das Minas Gerais e ia ao Rio de Janeiro, de onde seguia para outras regiões do Brasil, tendo sua decadência com o fim do ciclo, levando muitas fazendas à falência. Hoje elas abrigam criação de pecuária leiteira, outras ainda a produção do café e outras vivem como belíssimas pousadas. Além do café, o trabalho escravo foi muito usado na construção da cidade que, em seu estilo colonial teve das mãos dos escravos a construção de muitos monumentos, dentre eles a já citada a Ponte dos Arcos e o Túnel que chora.

O turismo e o reconhecimento de Conservatória torna-se então mais intenso com a tradição das serenatas. Conta-se que esta tradição nasceu com um romântico professor de música que tocava violino em uma noite enluarada até que atraiu espectadores. Aos poucos, outros músicos vinham de lugares distantes e passaram a acompanhar as serenatas do professor.

É criado, então, o Museu da Seresta pelos irmãos Joubert e José Borges. Outro importante símbolo do lugar é a Maria Fumaça hoje estacionada em frente à antiga Estação Ferroviária de Conservatória, que abriga atualmente a rodoviária.

\section{Memória do projeto}

O Projeto foi desenvolvido entre os anos de 2010 e 2012 e é composto por várias etapas, divididas em pesquisas documentais e de campo. Em um estudo realizado a partir da análise dos resultados obtidos na pesquisa de campo, coletados através dos questionários, das entrevistas com comerciantes, hoteleiros, moradores, estudantes e professores e moradores, discutiu-se as relações da memória com o desenvolvimento de atividades culturais e turísticas dos distritos de Conservatória (município de Valença) e Ipiabas (município de Barra do Piraí).

A análise dos dados empíricos foi realizada à luz de estudos teóricos sobre memória, identidade, poesia, música, teologia, dentre outros. Como já se antecipou o trabalho desenvolvido tem uma forte natureza interdisciplinar, contando com a participação de três pesquisadores da área das ciências humanas: literatura, história e teologia.

Esse projeto permitiu que se percebesse, além da utilização da memória enquanto recurso, a profundidade e a importância das discussões sobre a interdisciplinaridade, pois as pesquisas documentais e as atividades de campo realizadas mostraram como o diálogo interdisciplinar permite que haja uma maior abrangência nas ações que visam ao desenvolvimento (social e cultural) de importantes regiões do Brasil. A interdisciplinaridade, por sua própria natureza, transforma-se em um potente instrumento na busca de auxiliar atores sociais e grupos a atingir suas metas, sejam elas culturais, econômicas, educacionais, artísticas, turísticas, ou de qualquer outra natureza.

Através da coleta de informações e do trabalho com oficinas nas instituições de ensino de Ipiabas e Conservatória, foram estudados aspectos da memória coletiva, tendo como focos temáticos a seresta e a serenata. Justifica-se o ponto de partida do projeto na música por ser Conservatória considerada a "Capital da seresta e da serenata". Torna-se importante destacar, aqui, que, de acordo com os seresteiros e estudiosos locais, a seresta se diferencia da serenata pelo fato de que a primeira se realiza em recintos fechados, enquanto a segunda (mais propriamente a peculiaridade de Conservatória) se relaciona ao cortejo musical noturno, que vai pelas ruas interpretando canções de amor, sem acompanhamento de instrumentos de percussão.

Uma das peculiaridades das atividades realizadas pelo Projeto foi a de trabalhar com questões culturais, envolvendo jovens e idosos, visando à reflexão sobre as identidades e sua íntima relação com a memória e com a cultura. A problemática da memória foi aprofundada levando em consideração o estudo das histórias contadas, da "rememoração" dos idosos (lembrando aqui de um termo de Walter Benjamin ${ }^{4}$ ) e das perspectivas dos jovens a partir da exposição da importância da tradição cultural para o desenvolvimento da região, não apenas em termos econômicos, como educacionais e culturais.

A partir dessa visão, a memória é entendida aqui, principalmente, como ponto de partida para a criação de atividades de geração de renda. $\mathrm{O}$ turismo tem sido o campo que mais tem aproveitado 
essa característica da memória (e da cultura) enquanto recurso ${ }^{5}$. A memória coletiva influencia a memória individual ${ }^{6}$, e é nessa relação entre o individual e o coletivo que a "tradição" se construiu na região. Tal fato se deu a partir, principalmente, do trabalho de dois seresteiros, os irmãos José e Joubert Borges, realizado ao longo de décadas ${ }^{7}$. Ao fundar o Museu da Seresta em sua própria casa, o seresteiro José Borges criava um "local" para a memória da seresta e da serenata. Nesse "local de cultura" a memória armazenada não apenas auxiliou na preservação das canções do passado, como atuou como impulsionadora do desenvolvimento econômico de Conservatória e do seu entorno ${ }^{8}$.

Em Conservatória, em suas procissões sonoras noturnas (nas serenatas) as "memórias" "se encontram" nas canções que remetem os idosos aos seus ídolos do passado, às suas canções prediletas 9 . O passado, "reinventado", traz para o presente, nas vozes dos seresteiros, passagens importantes, guardadas na memória dos que seguem o cortejo musical ${ }^{10}$. Para aqueles que adicionam às lembranças dos áureos tempos do rádio e, mesmo na releitura das modinhas do século XIX, o cortejo os leva muito além dos logradouros da "capital da serenata”. Os visitantes viajam, portanto na memória, com a memória, ao encontro da memória.

\section{A observação}

Notamos que tanto em Ipiabas, como em Conservatória, os patrimônios material e imaterial são pouco percebidos pelos moradores e quando o são pelos visitantes tem sempre um olhar turístico e menos de uma percepção identitária. Os monumentos erguidos, os casarios construídos, possuem uma história já reveladora por si.

Há que se ressaltar que acreditamos como Rama que existem na cidade dois tipos de encontro: um físico e um simbólico, mas este nem todos percebem, sejam por estarem fora literalmente da cidade, ou simplesmente fora do espírito da "cidade letrada". Passam pela cidade, pelas ruelas, mas não compreendem o que vêem. Às vezes, as pessoas não têm nem tempo de as perceberem. $\mathrm{O}$ tempo e a preocupação consigo fazem com que os indivíduos por vezes se percam em si mesmos.

Neste sentido, percebemos que os habitantes da cidade estão mediados por lembranças e novas apreensões quando nela transitam. Há um misto de imagens que vão formando as identidades deste homem e a da própria cidade. No texto "Os passos perdidos: cidade e mito?" de Beatriz Jaguaribe ${ }^{11}$, ao citar Alejo Carpentier, mostra como este autor observa as latino-americanas e as classifica como carecedora de uma tradição arquitetural. Entende estas cidades como não possuindo um estilo como as europeias e, por isso mesmo, criando um novo estilo. Para ele estas cidades fazem uma equação de "destruição/construção com o esquecimento".

Enquanto são espaços não capturados pela população que vive, pela que visita nos fins de semana funciona como uma tradição já esperada. Estamos nos referindo, portanto, a um espaço de construção e manutenção de memória, onde se entrecruzam temporalidades e espacialidades diversas, definindo uma identidade, pela construção, ou até a invenção da tradição ${ }^{12}$ que interessa ao poder estabelecido e que serve a um projeto idealizado por este mesmo poder. A memória, então, se relaciona com o passado, o presente e o futuro a partir de um princípio dialetizador.

De outra forma, alguns espaços estavam cada vez mais difíceis de serem encontrados na cidade, decorrente da tentativa de se selecionar o que lembrar. Na cidade moderna, segundo Giulio Carlo Argan ${ }^{13}$ o passado é muitas vezes um ciclo histórico já encerrado, do qual nem tudo pode ser conservado. A escolha passa então a ter uma importância radical.

Segundo Claudia Ricci ${ }^{14}$, a composição arquitetural e aqui compreendemos a tradição como um todo, principalmente a musical, seria como se o presente buscasse construir uma história de seu passado ao mesmo tempo como se quisesse escrever outra história. A que ficará para outras gerações. A cultura da cidade tenta desta forma, tornar-se documento histórico, mostrando em suas inscrições, um tempo e um espaço que queriam representar e um que queriam apresentar. A cidade poderia ser lida através destas tradições. As pedras, os desenhos, as músicas, os bares, são textos escritos pelos moradores.

A análise do conjunto arquitetônico de Conservatória opera com a noção de memória como reconstrução de um passado, principalmente pelo que é posto em relevo. Movimento fundamental para a antecipação de um projeto de futuro, no caso, ordenado pelos valores identificados com um possível progresso. Tão logo, pretende-se relacio- 
nar questões referidas à memória, com a construção da identidade que se forja na cidade, para ela própria e para a cultura popular que a representa. Por último, busca-se uma aproximação da memória em sua relação com a ideia de projeto e com as expressões desse projeto em cada um dos edifícios-monumentos e nas distintas versões sobre seu significado na cidade.

$\mathrm{O}$ arquiteto, assim, transforma-se em historiador, quando relata o fato, quando seleciona o que pretende, ou não, fazer em sua obra. Deste modo mostra sua individualidade frente às demais, construindo um estilo próprio e ao mesmo tempo projeta-se em uma atitude diante da história. Representa ou deixa de representar um tempo e um espaço e está preocupado em olhar para trás, mas em registrar o futuro.

Neste sentido, a história destas cidades torna-se aquela que seleciona o que deve ser ou não ser lembrado ao mesmo tempo em que define as formas do futuro antecipado, confirmando assim a hipótese que articula necessariamente memória, identidade e projeto como formas de negociação com a realidade ${ }^{15}$.

Outra preocupação que identificamos e que se direciona mais exatamente para o caso de Conservatória, é a questão da transformação das identidades da população jovem e sua relação com uma memória e um projeto que dão sentido ao fato do deslocamento físico e às ideias de transferência e fragmentação da sociedade. Como tais moradores acabam sendo estigmatizados e que tipos de representações sociais se fazem deles, já que as serenatas são a "alma" da Cidade e muitos jovens não se sentem contemplados? Como as autoridades públicas lidam com esta questão quando um problema tópico torna-se um problema social? Este tema mostra a relação com a memória social, a busca de uma identidade, no que tange ao processo de uma possível exclusão do jovem.

Embora Conservatória demonstre uma das formas de reação à rápida urbanização, também traz à tona a preservação de vestígios do início do século XX que começa a incomodar a juventude. Entre o legado deixado pelos seresteiros e a recepção feita pelos jovens locais está a querela do que fazer com a tradição? Ou como manifestar essa tradição sob um olhar mais questionador do jovem do século XXI?
Como reunir tradição e modernidade e preservar o passado? E em Ipiabas outras perguntas surgem: como reconhecer o cenário como seu? Como entender a história construída da cidade como algo que, na verdade, conta a história individual e a memória coletiva e afetiva das famílias que ali estão?

Deste modo, observamos como principal questão o desejo de ver a cidade e descobrir seu sentido. $\mathrm{O}$ presente de cada local reinventa-se a cada momento na tentativa de assumir por um lado a perspectiva contemplativa que permite olhar, ver, compreender e de outro encontrar o sentido do que não pode ser percebido somente com o olhar.

Michel de Certeau mostra que a cidade pode ser entendida como um texto e para isso é necessário que alguém o escreva. Em Ipiabas e Conservatória seus autores podem ser os anônimos caminhantes, como os turistas ou os moradores idosos ou adolescentes e a escrita são seus passos, ainda que por vezes nunca tenham consciência da obra que reescrevem. Os espaços percorridos tornam-se caminhos cantados e os passos não percebem suas marcas na cidade. Uma face das Cidades é assim descoberta enquanto a outra se esconde: a Ipiabas do jongo, da capoeira, da tradição africana não é a mesma das crianças que não a reconhecem. A Conservatória movimentada de sexta e sábado não é a ideia do todo, a face de domingo a quinta permanece oculta.

Podemos perceber que nas cidades problemas como articulação de interesses, solidariedade e legitimação da autoridade, aparecem de forma singular, embora sejam questões universais. Deste modo, os conceitos devem ser utilizados, mas como instrumentos que auxiliam a entender os processos históricos do seu desenvolvimento e não encarados como receita infalível que deva se prender.

As cidades de Conservatória e Ipiabas mostram-se hoje modernas e tradicionais em suas ações cotidianas. Representam-se deste modo para o morador e para o visitante. Para tanto recorremos a Reinhard Bendix ${ }^{16}$ em que tradição e modernidade não fazem parte de algo que se caracterize como causa e consequência, mas se combinam. As transformações que sofrem as sociedades estão ligadas a seus estados anteriores. Muito embora, um grande traço da modernidade seja ideia 
de contemporaneidade, onde se deve "viver o seu tempo", deve-se também observar o que se articulou anteriormente para se chegar a esse tempo.

\section{Agradecimentos}

À FAPERJ pelo apoio ao Projeto.

Aos moradores de Conservatória e Ipiabas que contribuíram para a execução do Projeto.

\section{Contribuições dos Autores}

Cada um dos autores contribuiu uniformemente e com interesses próximos, pois são pesquisadores do Projeto apoiado pela FAPERJ, com duração entre os anos de 2010 e 2012 e docentes-pesquisadores de um Programa de Pós-Graduação inserido na área Interdisciplinar da CAPES.

\section{Referências}

1. BOSI,Eclea. O tempo vivo da memória.São Paulo: Ateliê Editorial, 1996.:53.

2. NORA, Pierre. Entre Memória e História: a Problemática dos Lugares. Tradução: Yara Aun Khoury. São Paulo: Revista do Programa de Estudos Pós-Graduados em História. PUC, 1993.

3. NORA, Pierre. Entre Memória e História: a Problemática dos Lugares. Tradução: Yara Aun Khoury. São Paulo: Revista do Programa de Estudos Pós-Graduados em História. PUC, 1993: 22.

4. BENJAMIN, Walter. A imagem de Proust. Walter Benjamin. Obras escolhidas. Magia e técnica, arte e política. Trad. Sérgio Paulo Rouanet. São Paulo: Brasiliense, 1987.

5. YUDICE, George. A conveniência da cultura na era global. Belo Horizonte: Editora UFMG, http://www.portalsaofrancisco.com.br/alfa/ciclo-do-cafe/ipiabas.php, acessado em 28 de agosto de 2012.

6. HALBWACHS, Maurice. A memória coletiva. Tradução de Beatriz Sidou. São Paulo: Centauro, 2006.

7. MAGNO, Marluce. Projeto Conservatória meu amor. Jovem também gosta de serenata. Ed. Marluce Magno, Valença, 2005. e MAGNO, Marluce. Projeto Conservatória meu amor. Jovem também gosta de serenata. Vol. 2. Valença: Ed. Marluce magno, 2011.

8. MAGNO, Marluce. Projeto Conservatória meu amor. Jovem também gosta de serenata. Ed. Marluce Magno, Valença, 2005. e MAGNO, Marluce. Projeto Conservatória meu amor. Jovem também gosta de serenata. Vol. 2. Valença: Ed. Marluce Magno, 2011.

9. MAGNO, Marluce. Projeto Conservatória meu amor. Jovem também gosta de serenata. Ed. Marluce Magno, Valença, 2005.

10. BOSI, Eclea. O tempo vivo da memória. São Paulo: Ateliê Editorial, 1996.
11. JAGUARIBE, Beatriz. "Os passos perdidos: cidade e mito?", in. CIDADE. Revista do Patrimônio Histórico Artístico Nacional. Número 23/1994: 247.

12. HOBSBAWN, Eric e RANGER, Terence. A Invenção das Tradições. São Paulo: Paz e Terra, 1997.

13. ARGAN, Giulio Carlo. História da Arte como história da cidade. São Paulo: Martins Fontes, 1995 :77.

14. RICCI, Claudia. Adolfo Morales de los Rios. Uma História Escrita com Pedras e Letras. Dissertação de Mestrado. Rio de Janeiro: PUC/RJ, 1996.

15. OVELHO, Gilberto. "Memória, Identidade e Projeto". In: Projeto e Metamorfose. Antropologia das Sociedades Complexas. Rio de Janeiro: Zahar, 1994.

16. BENDIX, Reinhard. Construção Nacional e Cidadania. Estudos de nossa ordem social em mudança. São Paulo, EdUsp, 1996.

\section{Abstract}

This paper presents a study of two cities, part of a research and community Project supported by FAPERJ in 2010. This research addresses the recognition of the meaning of history, belonging, identity and building a brand that establishes a link not only between the city and its dwellers but also between the city and its visitors. This is the history of Ipiabas and Conservatória, two districts in the State of Rio de Janeiro, Brazil. They are full of history, but their full , manifestations either collide with the lack of recognition of customs that truly represent the city, its identily, as in the case of Ipiabas or get confused between what tradition is and what to expect in terms of modernity, as in the case of Conservatória.

Keywords: History; Memory; Belonging; Ipiabas; Conservatório 